\title{
Appendiceal mucinous cystadenoma presenting as abdominal internal hernia: a case report
}

\author{
Mao Ye ${ }^{1}$, Binglong Bai ${ }^{1}$, Liangji Lu ${ }^{2}$, Dapeng Xiang ${ }^{1}$, Zhiyu Li $^{1}$ \\ ${ }^{1}$ Department of General Surgery, ${ }^{2}$ Department of Radiology, The Second Affiliated Hospital of Zhejiang University School of Medicine, Hangzhou \\ 310052, China \\ Correspondence to: Zhiyu Li. Department of General Surgery, The Second Affiliated Hospital of Zhejiang University School of Medicine, 1511 \\ Jianghong Road, Binjiang, Hangzhou 310052, China. Email: zrlizy@zju.edu.cn.
}

\begin{abstract}
Appendiceal mucinous neoplasm is a rare form of appendix disorder of all appendectomies. Patients may present with many non-special symptoms which the right low quadrant pain is the mostly reported. We reported a case of 70-year-old man who was admitted to emergency for abdominal pain and progressive aggravation of peritoneal irritation sign. Computed tomography (CT) revealed incomplete intestinal obstruction with volvulus of partial small intestine in right lower quadrant, and internal hernia was suspected and simple appendectomy was performed followed. The postoperative pathologic diagnosis was mucinous cystadenoma with negative cutting margin. During three-year follow-up, the patient was in good condition and there was no sign of recurrence.
\end{abstract}

Keywords: Appendiceal mucinous cystadenoma; abdominal internal hernia

Submitted Jan 13, 2019. Accepted for publication Oct 14, 2019.

doi: $10.21037 /$ tcr.2019.10.10

View this article at: http://dx.doi.org/10.21037/tcr.2019.10.10

\section{Introduction}

Regarding to mucinous adenocarcinoma, there were four disease categories: Retention mucoceles, Cystadenomas, cystadenocarcinomas and Mucinous adenocarcinomas without mucocele (1). Appendiceal mucocele is a rare lesion which represents cystic dilation of appendiceal lumen due to accumulation of mucous (2). Appendiceal mucocele accounted $0.2-0.4 \%$ of appendectomies $(3,4)$ and it can be classified into three groups $(5,6)$ : (I) focal or diffuse mucosal hyperplasia, with no epithelial atypia and mild distention of the lumen; (II) mucinous cystadenoma, exhibiting some degree of epithelia atypia and marked distention of the lumen; (III) mucinous cystadenocarcinoma, with stromal invasion by glands and/or epithelial cells in peritoneal implants. The clinical manifestation is non-special. It may present with abdominal pain, nausea, vomiting, mass of ovary, intestinal obstruction, ureteral compression and so on (7). Due to the absence of characteristic clinical symptoms and some of which may be manifestations of abdominal internal hernia, it needs comprehensive examinations to diagnose (8). Well, regarding to abdominal internal hernia, there are characteristic signs of CT scan, so generally it can be confirm diagnosed by the CT scan (9). Herein we present a case of appendiceal mucinous cystadenoma presenting as abdominal internal hernia to provide much more information for clinical diagnosis and therapy.

\section{Case presentation}

\section{Clinical presentation of patient}

A 70-year-old man was admitted to our emergency room for abdominal pain with nausea and vomiting, accompanied with abdominal distension for 4 days. The patient had been treated conservatively in local hospital, however, without any improvements. He denied family history of colorectal cancer or inflammatory bowel disease. Physical examination showed soft abdomen with tenderness in upper and right lower quadrant, without peritoneal irritation sign, and there was no palpable abdominal bump. No special sign was showed on ultrasound except dilation of intestine. CT scan (Figure 1) was taken when transferred and there were no signs of significantly expanded intestine segments. 


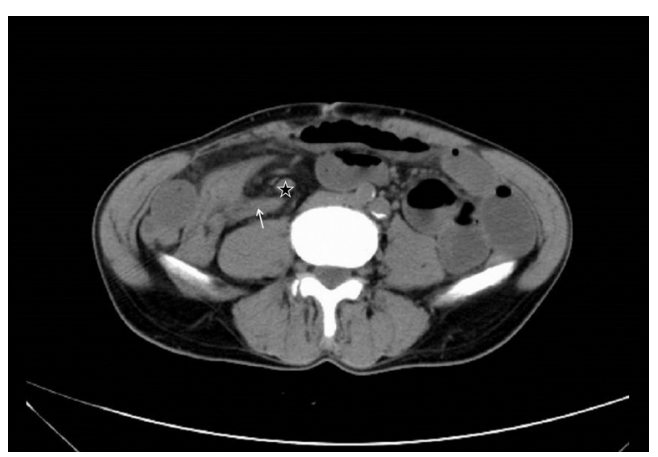

Figure 1 CT scan report of intestine. Segments of intestine haven't yet expanded significantly at the first time of CT scan. Asterisk, small intestine; arrow, appendix.

Tumor markers including CEA (carcinoembryonic antigen, CEA), AFP (alpha fetoprotein), CA199 (cancer antigen 199, CA199), CA125 (cancer antigen 125, CA125), CA242 (cancer antigen 242, CA242) were tested to evaluate whether there was tumor and the results were all in normal range. Full blood count showed normal range of white blood cell and neutrophils, so conservative support care was applied. Unfortunately, the pain aggravated and peritoneal irritation sign came out the next day. Ultrasound was taken and the results showed that expansion of abdominal intestinal canal and enhanced CT (Figure 2) was taken immediately which implied incomplete intestinal obstruction with volvulus of partial small intestine in right lower quadrant, and internal hernia was suspected.

\section{Diagnosis, treatment and clinical outcome}

The patient met the indications of operation and an emergency surgery was conducted to relieve these symptoms. A median incision was performed. It was found that the tip of appendix, which was in normal morphology, was adhered to the intestine that about $110 \mathrm{~cm}$ to the ileocecum and thus formed a hernia ring. Some segments of intestine and colon fell into the ring as hernia contents. The blood supply of intestine and colon which formed hernia contents was normal. No bumps or ascites was found. The adhesion was dissected, and appendectomy was proceeded routinely. The postoperative pathologic diagnosis was mucinous cystadenoma with negative cutting margin (Figure 3).

Patient returned to the ward with stable vital signs after surgery. All symptoms and physical signs of mucinous cystadenoma disappeared. The patient was discharged from hospital without any complications after one week. During three-year follow-up, the patient was in good condition and without signs of recurrence. In the 33rd month, CT-scan (Figure 2D) was performed again to evaluate the patients' condition and the results showed that the morphology of intestine was normal and without cystic dilation.

\section{Discussion}

Appendiceal mucinous cystadenoma is characterized by cystic dilation of appendiceal lumen due to accumulation of mucous. Well, in this case, the pathogenesis and related examination including ultrasound and CT scan of the patient didn't support the diagnosis of appendiceal mucinous cystadenoma (10-12). Instead, ultrasound was taken to evaluate the patient's situation and the results showed that expansion of abdominal intestinal canal which support the diagnosis of abdominal internal hernia $(13,14)$ and the CT scan indicated that the patient was diagnosed with suspicion as abdominal internal hernia for the reason that it showed the typical changes include abnormal shape of intestines, translocated position, gathered intestinal loops with different forms and centralized blood vessels and shrinking mesenteries at the entrance of hernia $(15,16)$, so the patient was diagnosed as abdominal internal hernia at first according to the symptoms, signs and imaging examination.

The preoperative imaging diagnosis is very important because it will guide the operation, evaluate the situation and help doctor to make the correct decisions under that condition (17-19). Regarding to this patient, we gave conservative treatment based on the preoperative imaging test and there was no improvements after conservative treatment. Then we conduct an operation for the patient. Although the diagnosis was almost clear, we found it may be another disease during the operation as describes in another case $(20,21)$. As the appendix may be sheltered by inflated bowls which would present an illusion of abdominal internal hernia and US examination would not reveal the actual disease as in our case, so CT scan is very important and necessary.

Clinically, there were many imaging manifestations for appendiceal mucinous cystadenoma, like curvilinear mural calcification and so on (22-30). And usually the benign and malignant could be told with the typical features of CT which is the enhancing nodular lesion in the wall $(25,31,32)$. Regarding to the diagnosis of appendiceal mucinous cystadenoma, ultrasound shows the location of 

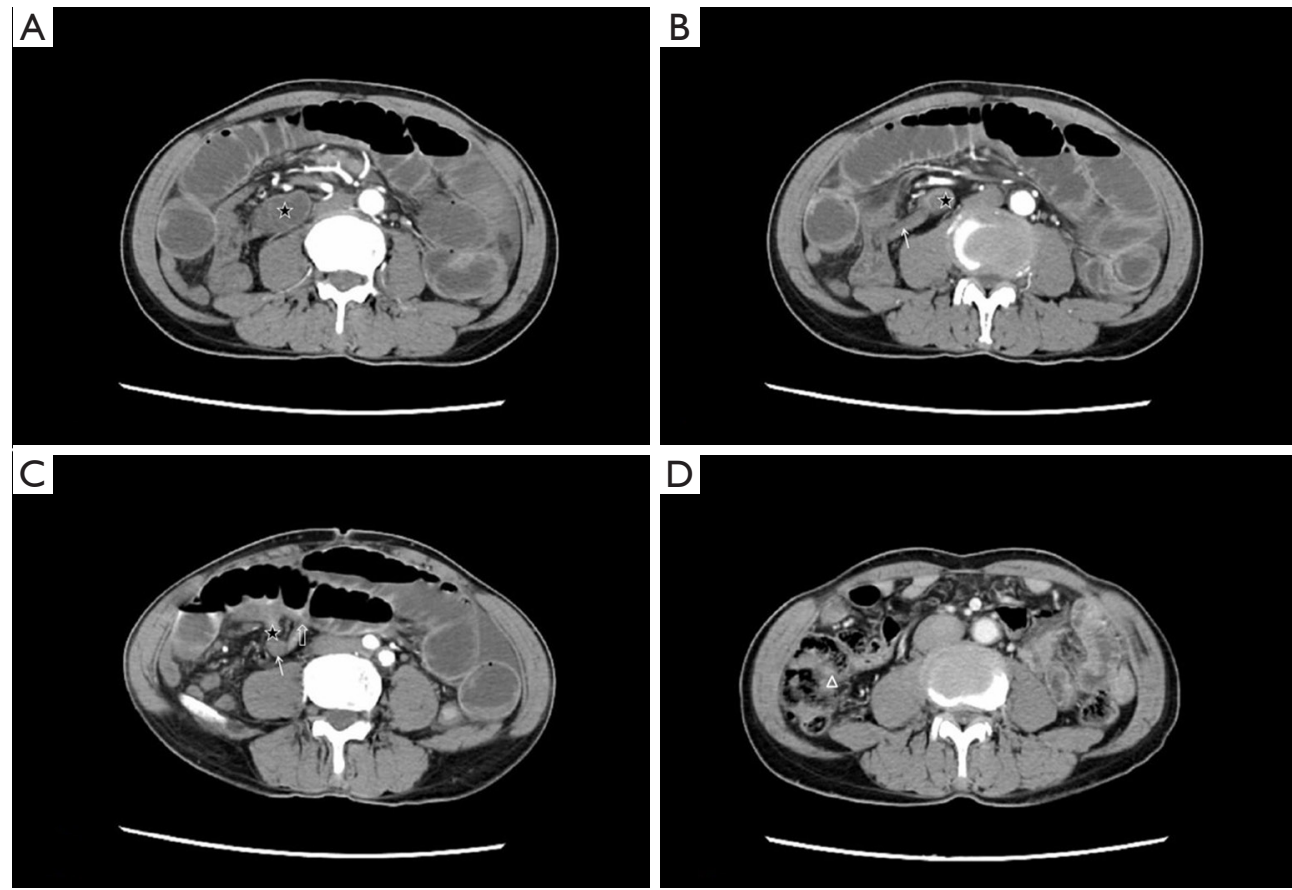

Figure 2 Enhanced CT scan report of intestine. (A) proximal dilatation of small intestine. It caused by incomplete intestinal obstruction with volvulus of partial small intestine before surgery; (B) small intestine and appendix affected by obstruction before surgery; (C) hernia filled by small intestine before surgery; (D) cystic dilation disappeared after surgery. Asterisk, small intestine; arrow, appendix; hollow arrow, synechia of small intestine with appendix; triangle, ileocecal junction.

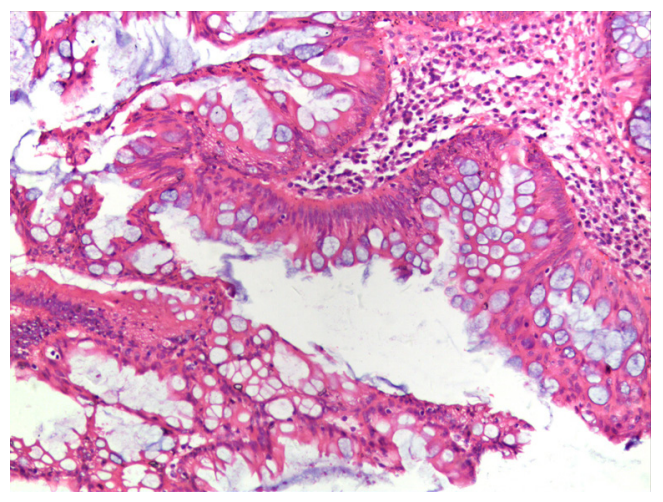

Figure 3 Postoperative pathology of lesion. HE: $\times 200$.

mucocele which usually situated at the proximal appendiceal orifice causing distal lumen obstruction (30) and CT scan, the most helpful imaging examination $(5,33)$, shows the density of contents, complications like inflammation and compression, relationship between peri appendiceal tissue and pseudomyxoma (34). And appendiceal mucinous cystadenoma should be differentially diagnosed from ovary cyst, lymphocele, abscess, enteric duplication cyst, hematoma and hydrosalpinx $(25,35)$. However, there is no typical US or CT sign in our case for the reason that the patient was in early stage of the disease when taken these examinations.

Operation should be proceeded gently in case of iatrogenic rupture of the cystadenoma and spreading of mucin to form pseudomyxoma peritonei. The surgical treatment should be based on the finding of tumor and the suspected pathology (36-38). Simple appendicectomy is advised for small, uncomplicated lesions while the right hemicolectomy and caecum resection is recommended for mucoceles with a diameter greater than $2 \mathrm{~cm}$ and positive margin at the appendectomy site (5,37-40). The five-year survival rate is almost $100 \%$ for benign pattern while varies from $30 \%$ to $80 \%$ for malignant forms respectively (5).

To our best knowledge, no case of mucinous cystadenoma of appendix presenting as abdominal internal hernia has been reported. Abdominal internal hernial may cause disorder of blood circulation and result in necrosis of intestine, severe peritonitis, sepsis and so on. Therefore, it is very important to identify the lesion before the following treatment. Although the technology is advanced, physical 
examination must not be disregarded in emergency case. It can show the change of abdominal disorder dynamically.

\section{Conclusions}

Mucinous cystadenoma of the appendix is rarely diagnosed before operation. It can present many nonspecific types of sign. In diagnostic procedure, abdominal sign should be noticed continuously and enhanced CT scanning is helpful to identify the disease. Surgical procedure must be very careful to prevent iatrogenic rupture of the mucocele and avoid spreading mucin to peritoneal cavity.

\section{Acknowledgments}

Funding: None.

\section{Footnote}

Conflicts of Interest: All authors have completed the ICMJE uniform disclosure form (available at http://dx.doi. org/10.21037/tcr.2019.10.10). The authors have no conflicts of interest to declare.

Ethical Statement: The authors are accountable for all aspects of the work in ensuring that questions related to the accuracy or integrity of any part of the work are appropriately investigated and resolved. All procedures performed in studies involving human participants were in accordance with the ethical standards of the institutional and/or national research committee(s) and with the Helsinki Declaration (as revised in 2013). Written informed consent was obtained from the patient for publication of this manuscript and any accompanying images.

Open Access Statement: This is an Open Access article distributed in accordance with the Creative Commons Attribution-NonCommercial-NoDerivs 4.0 International License (CC BY-NC-ND 4.0), which permits the noncommercial replication and distribution of the article with the strict proviso that no changes or edits are made and the original work is properly cited (including links to both the formal publication through the relevant DOI and the license). See: https://creativecommons.org/licenses/by-nc-nd/4.0/.

\section{References}

1. Wackym PA, Gray GF Jr. Tumors of the appendix: I.
Neoplastic and nonneoplastic mucoceles. South Med J 1984;77:283-7.

2. Xu ZS, Xu W, Ying JQ, et al. Mechanical intestinal obstruction secondary to appendiceal mucinous cystadenoma: A case report and brief review. Medicine (Baltimore) 2017;96:e6016.

3. González Moreno S, Shmookler BM, Sugarbaker PH. Appendiceal mucocele. Contraindication to laparoscopic appendectomy. Surg Endosc 1998;12:1177-9.

4. Khan MR, Ahmed R, Saleem T. Intricacies in the surgical management of appendiceal mucinous cystadenoma: a case report and review of the literature. J Med Case Rep 2010;4:129.

5. Rouchaud A, Glas L, Gayet M, et al. Appendiceal mucinous cystadenoma. Diagn Interv Imaging 2014;95:113-6.

6. Higa E, Rosai J, Pizzimbono CA, et al. Mucosal hyperplasia, mucinous cystadenoma, and mucinous cystadenocarcinoma of the appendix. A re-evaluation of appendiceal "mucocele". Cancer 1973;32:1525-41.

7. Salemis NS, Nakos G, Katikaridis I, et al. Synchronous occurrence of appendiceal mucinous cystadenoma, with colon adenocarcinoma and tubulovillous rectal adenoma: Management and review of the literature. J Nat Sci Biol Med 2016;7:173-5.

8. Shiihara M, Ohki T, Yamamoto M. Preoperative Diagnosis and Surgical Approach of Appendiceal Mucinous Cystadenoma: Usefulness of Volcano Sign. Case Rep Gastroenterol 2017;11:539-44.

9. B B SK, Jasuja P. Appendiceal mucocele-A rare case report. Int J Surg Case Rep 2019;58:21-5.

10. Emre A, Sertkaya M, Kale İT. Clinicopathological analysis of appendiceal mucinous tumors: A single-center experience. Turk J Surg 2017;33:274-8.

11. Lynch K, Cho S, Andres R, et al. Pre-operative Identification and Surgical Management of the Appendiceal Mucocele: A Case Report. W V Med J 2016;112:28-30.

12. Mastoraki A, Sakorafas G, Vassiliu P, et al. Mucocele of the Appendix: Dilemmas in Differential Diagnosis and Therapeutic Management. Indian J Surg Oncol 2016;7:86-90.

13. Berle M, Dahlslett KH, Kavaliauskiene G, et al. Internal abdominal hernia. Tidsskr Nor Laegeforen 2017;137. doi: 10.4045/tidsskr.17.0090.

14. Goudsmedt F, Deylgat B, Coenegrachts K, et al. Internal hernia after laparoscopic Roux-en-Y gastric bypass: a correlation between radiological and operative findings. 
Obes Surg 2015;25:622-7.

15. Dilauro $M$, McInnes MD, Schieda N, et al. Internal Hernia after Laparoscopic Roux-en-Y Gastric Bypass: Optimal CT Signs for Diagnosis and Clinical Decision Making. Radiology 2017;282:752-60.

16. Altieri MS, Pryor AD, Telem DA, et al. Algorithmic approach to utilization of CT scans for detection of internal hernia in the gastric bypass patient. Surg Obes Relat Dis 2015;11:1207-11.

17. Cox J, Hancock H, Maier R, et al. Multidetector CT improving surgical outcomes in breast cancer (MISO-BC): A randomised controlled trial. Breast 2017;32:217-24.

18. Donahoe LL, Nguyen ET, Chung TB, et al. CT-guided microcoil VATS resection of lung nodules: a single-centre experience and review of the literature. J Thorac Dis 2016;8:1986-94.

19. Yang $\mathrm{Z}, \mathrm{Xu} \mathrm{W}, \mathrm{Ma} Y$, et al. (18)F-FDG PET/CT can correct the clinical stages and predict pathological parameters before operation in cervical cancer. Eur J Radiol 2016;85:877-84.

20. Agrusa A, Romano G, Galia M, et al. Appendiceal mucinous neoplasms: an uncertain nosological entity. Report of a case. G Chir 2016;37:86-9.

21. Handler M, Anand N, Wei L, et al. Adenocarcinoma of the Appendix Presenting as a Palpable Right Thigh Mass. J Radiol Case Rep 2017;11:20-9.

22. Choi SY, Park S, Kim KH, et al. Heterotopic ossification in appendiceal mucinous neoplasms: clinicopathological characteristics of 3 cases. Malays J Pathol 2016;38:49-54.

23. Wei-Ming L, Chih-Hui L, Kuo LM, et al. Intussusception secondary to a giant appendiceal mucocele: preoperative diagnosis by multi-slice computed tomography. Abdom Imaging 2010;35:428-30.

24. Shukunami K, Kaneshima M, Kotsuji F. Preoperative diagnosis and radiographic findings of a freely movable mucocele of the vermiform appendix. Can Assoc Radiol J 2000;51:281-2.

25. Kim SH, Lim HK, Lee WJ, et al. Mucocele of the appendix: ultrasonographic and CT findings. Abdom Imaging 1998;23:292-6.

26. Okuda I, Matsuda M, Noguchi H, et al. Massive mucinous cystadenoma of the appendix with intussusception in an adult: usefulness of reconstructed computed tomography images. Radiat Med 2008;26:88-91.

27. Coulier B, Pestieau S, Hamels J, et al. US and CT diagnosis of complete cecocolic intussusception caused by an appendiceal mucocele. Eur Radiol 2002;12:324-8.

28. Zissin R, Gayer G, Fishman A, et al. Synchronous mucinous tumors of the ovary and the appendix associated with pseudomyxoma peritonei: CT findings. Abdom Imaging 2000;25:311-6.

29. Fallon MJ, Low VH, Yu LL. Mucinous cystadenoma of the appendix with unusual sonographic appearances. Australas Radiol 1994;38:339-41.

30. Zhou ML, Yan FH, Xu PJ, et al. Mucinous cystadenoma of the appendix: CT findings. Chin Med J (Engl) 2006;119:1300-3.

31. Wu RL, Ali S, Sarkar FH, et al. Identification of Differentially Expressed miRNAs in Appendiceal Mucinous Cystadenocarcinoma from Mucinous Cystadenoma. J Cancer Sci Ther 2015;7:328-35.

32. Rymer B, Forsythe RO, Husada G. Mucocoele and mucinous tumours of the appendix: A review of the literature. Int J Surg 2015;18:132-5.

33. Malya FU, Hasbahceci M, Serter A, et al. Appendiceal mucocele: clinical and imaging features of 14 cases. Chirurgia (Bucur) 2014;109:788-93.

34. Devir C, Kebapci M, Temel T, et al. Comparison of 64-Detector CT Colonography and Conventional Colonoscopy in the Detection of Colorectal Lesions. Iran J Radiol 2016;13:e19518.

35. Honnef I, Moschopulos M, Roeren T. Appendiceal mucinous cystadenoma. Radiographics 2008;28:1524-7.

36. Lorenzon L, De Dominicis C, Virgilio E, et al. The appropriate management of an appendiceal mucocele. BMJ Case Rep 2015;2015. doi: 10.1136/bcr-2014-209045.

37. McFarlane ME, Plummer JM, Bonadie K. Mucinous cystadenoma of the appendix presenting with an elevated carcinoembryonic antigen (CEA): Report of two cases and review of the literature. Int J Surg Case Rep 2013;4:886-8.

38. García Lozano A, Vázquez Tarrago A, Castro García C, et al. Mucocele of the appendix: Presentation of 31 cases. Cir Esp 2010;87:108-12.

39. Ashrafi M, Joshi V, Zammit M, Intussusception of the appendix secondary to mucinous cystadenoma: A rare cause of abdominal pain. Int J Surg Case Rep 2011;2:26-7.

40. Papadopoulos IN, Christodoulou S, Kokoropoulos P, et al. Perforated mucinous cystadenoma of the vermiform appendix: an overview in reasoning clinical decisions. BMJ Case Rep 2011;2011. doi: 10.1136/bcr.02.2011.3902.

Cite this article as: Ye M, Bai B, Lu L, Xiang D, Li Z. Appendiceal mucinous cystadenoma presenting as abdominal internal hernia: a case report. Transl Cancer Res 2019;8(7):26672671. doi: $10.21037 /$ tcr.2019.10.10 